\title{
Simulating the Effects of Structural Parameters on the Hydraulic Performances of Venturi Tube
}

\author{
Yanqi Sun and Wenquan Niu \\ College of Water Resources and Architectural Engineering, Northwest A \& F University, Yangling, Shaanxi 712100, China
}

Correspondence should be addressed to Wenquan Niu, nwq@vip.sina.com

Received 19 December 2011; Accepted 17 January 2012

Academic Editor: Guan Heng Yeoh

Copyright () 2012 Y. Sun and W. Niu. This is an open access article distributed under the Creative Commons Attribution License, which permits unrestricted use, distribution, and reproduction in any medium, provided the original work is properly cited.

The effects of Venturi structural parameters on its hydraulic performance were studied, which provided theoretical basis for the design of Venturi injector. With an inlet diameter of $50 \mathrm{~mm}$, based on the method of computational fluid dynamics (CFD), the effects of the structural parameters (such as throat taper, throat contraction ratio, and throat length) on their hydraulic performance (such as outlet faceted average velocity, minimum pressure, and critical pressure) were studied under different inlet pressures and pressure differences between inlet and outlet. A power function relationship existed between the mean velocity in outlet section and pressure difference, with an approximate flow stance index of 0.53 . Minimum pressure occurred in the throat inlet wall and there was a linear relationship between the minimum pressure and the pressure difference at the inlet and outlet. The throat contraction ratio was the main factor on the effect of Venturi injector performance, which was positively correlated with outlet velocity, negatively to critical pressure, the minimal in-tube pressure, coefficient of local head loss, and fertilizer absorption ratio. For designing Venturi injector, contraction ratio should be reasonably selected according to the coefficient of local head loss and fertilizer absorption ratio.

\section{Introduction}

Drip irrigation is a controlled local irrigation. While irrigating, fertilizer mixed in water is delivered to the crop root zone, which not only saves fertilizer and a lot of labors, but also improves fertilizer use efficiency and reduces production costs. Fertilization device is one of the main devices in the drip irrigation system. At present, commonly applied devices for fertilization include pressure difference fertilizer applicator, fertilizer pumper, and Venturi injector [1-3].

Due to its simple structure, convenient operation, the Venturi injector has a wide application in the production agriculture. Therefore, the effects of structural parameters of the injector on its hydraulic performance were studied, which is important to improve and enhance its work performance [4]. Two-part Venturi tube was studied by Hou [5], Sha and Hou [6], Sheng [7], and Sun and Wu [8], and structural parameters of the Venturi tube were determined. Li et al. [9] and Jin et al. [10] investigated the relationship among throat pressure, front and back pressure difference, and designing parameters of paralleled Venturi tube, who also suggested the optimal selection of parameters of front and behind inclinations of paralleled Venturi tube. Chen et al. [11] and Wang et al. [12] employed CFD to determine the relationships between the structural parameters of the Venturi applicator and its fertilization performance and suggested that when the inlet pressure and the slot position keep constant, the suction of the Venturi injector would increase with the decrease of throat diameter and the length of contraction section, and the increase of slot diameter. However, few studies have reported aiming at the effects of Venturi structural parameters on its fertilization performance, and there is little theoretical information available on the design of Venture injectors with better fertilization performance and lower head loss.

The objective of this study was to determine the effects of structural parameters of Venturi tube on its hydraulic performance based on the method of CFD. Results of this study may provide theoretical basis for the design of better Venturi injector and may suggest a broader alternative for further researches on the effect of Venture structural parameters on the hydraulic performance. 


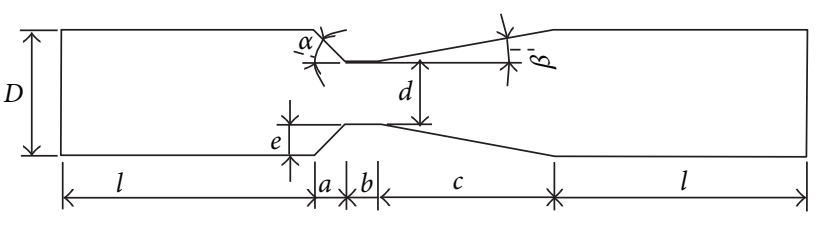

FIgURE 1: Structural diagram of Venturi injector.

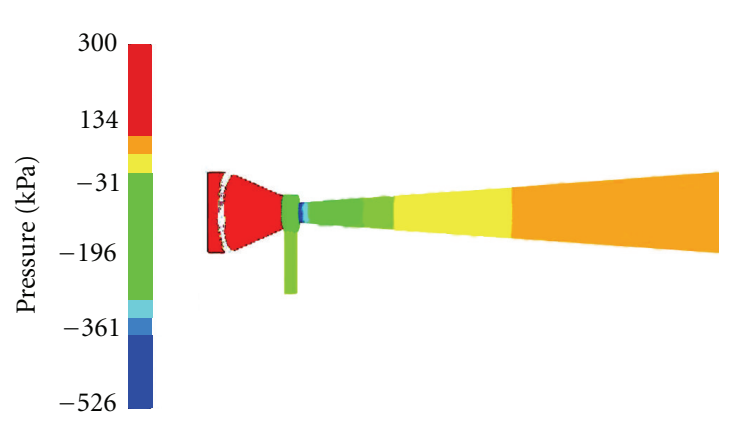

Figure 2: Pressure profile patterns of Venturi injector.

TABle 1: Structural Parameters of Venturi injector.

\begin{tabular}{lcccc}
\hline$D /(\mathrm{mm})$ & $\lambda_{1}$ & $\lambda_{2}$ & $\alpha /(\mathrm{rad})$ & $\beta /\left(^{\circ}\right)$ \\
\hline 50 & $0.25,0.30$ & $1.0,1.5,2.0$ & $1.57,2.09,2.62$ & 10 \\
& $0.40,0.50$ & & & \\
\hline
\end{tabular}

\section{Methods and Materials}

2.1. Physical Model and Parameters. In the structural diagram of Venturi injector, $D$ is inlet and outlet diameter $(\mathrm{mm}), l$ is inlet and outlet length $(\mathrm{mm}), a$ is contraction length $(\mathrm{mm}), b$ is throat length $(\mathrm{mm}), c$ is expansion length $(\mathrm{mm}), d$ is throat diameter $(\mathrm{mm}), e$ is radius difference between inlet and throat $(\mathrm{mm}), \alpha$ is contraction ratio ( $\mathrm{rad})$, and $\beta$ is expansion angle $\left({ }^{\circ}\right)$ (Figure 1 ).

For the structural parameters of Venturi injector (Table 1 ), the throat contraction ratio $\left(\lambda_{1}\right)$ is the ratio between the throat diameter and inlet diameter, namely, $\lambda_{1}=$ $d / D$; throat length-diameter ratio $\left(\lambda_{2}\right)$ is ratio between the throat length and the throat diameter, namely, $\lambda_{2}=b / d$. Based on a factorial experiment design of the structural parameters in Table 1, a total of 36 treatments were obtained. The simulations were conducted at different inlet pressures and pressure differences between inlet and outlet. The inlet pressures were $100,150,200,250$, and $300 \mathrm{kPa}$, respectively, and the outlet pressures are shown in Table 2.

2.2. Mathematical Model. Water flow in the Venturi injector could be regarded as incompressible, steady flow, which is consistent with mass and momentum conservation law. Therefore, the basic equations include the continuity equation (1) and the Navier-Stokes equation(2)

$$
\frac{\partial u}{\partial x}+\frac{\partial v}{\partial y}+\frac{\partial w}{\partial z}=0
$$

TABLE 2: Outlet pressures under the different inlet pressures of Venturi injector.

\begin{tabular}{lc}
\hline Inlet pressure/kpa & Outlet pressure/kpa \\
\hline 100 & $90,80,70,50,40$ \\
150 & $130,110,90,70,50$ \\
200 & $160,140,120,100,80$ \\
250 & $200,170,130,100,70$ \\
300 & $240,200,150,120,100$ \\
\hline
\end{tabular}

where $u, v, \omega(\mathrm{m} / \mathrm{s})$ means the flow rate component in $x, y, z$ direction, respectively

$$
\begin{aligned}
& \frac{\partial(\rho u)}{\partial t}+\nabla(\rho u U)=-\frac{\partial p}{\partial x}+\mu \nabla^{2} u+F_{x} \\
& \frac{\partial(\rho v)}{\partial t}+\nabla(\rho v U)=-\frac{\partial p}{\partial y}+\mu \nabla^{2} v+F_{y} \\
& \frac{\partial(\rho \omega)}{\partial t}+\nabla(\rho \omega U)=-\frac{\partial p}{\partial z}+\mu \nabla^{2} \omega+F_{z}
\end{aligned}
$$

where $t(\mathrm{~s})$ is time, $U(\mathrm{~m} / \mathrm{s})$ is velocity vector, $\rho\left(\mathrm{kg} / \mathrm{m}^{3}\right)$ is the water density, $p(\mathrm{~Pa})$ is pressure of fluid tiny body, $\mu(\mathrm{Pa} \cdot \mathrm{s})$ is dynamic viscidity coefficient of water, $F_{x}, F_{y}, F_{z}$ means component of mass force on unit volume at $x, y, z$, respectively. When the mass force is only the gravity and $Z$ axis is vertical, then comes $F_{x}=0, F_{y}=0$, and $F_{z}=-\rho g$.

According to microscale theory and experimental study, transition Reynolds number in small scale is less than that of the macroscale. When the flow channel was bended and variable, except at the part near the wall, other flows were the turbulent. Therefore, the standard $k-\varepsilon$ turbulence model was used for numerical simulation. In the $k-\varepsilon$ turbulence model, turbulent kinetic energy was $k$, dissipation ratio was $\varepsilon$.

2.3. Meshing. CFD software FLUENT6.2 was used for simulation analysis. In this software, differential equations could be simplified into algebraic equations via the finite volume method, one-order upwind difference scheme for its calculation. SIMPLE algorithm was employed for the calculation of noncoupling of pressure rate of the discrete equations. Convergence criteria were the second iteration residuals of the adjacent dependent variables. The twodimensional model was established using AutoCAD, with GAMBIT2.2.30 to mesh, each section set fully structured hexahedral grid of $1 \mathrm{~mm}$ diameter, generated about 30000 grids.

\section{Results and Discussions}

3.1. Pressure Difference and the Mean Velocity at Outlet CrossSection. According to the numerical simulation, the distributions in the flow and pressure fields of Venturi injector were obtained, and the outlet velocity and minimal intube pressure could be calculated. The relationship between pressure difference and the discharge velocity at outlet could be expressed as follows:

$$
v=k \cdot h^{x},
$$


TABLE 3: Regression coefficients of pressure differences and velocity of Venturi injector.

\begin{tabular}{|c|c|c|}
\hline Simulation & $k$ & $x$ \\
\hline M1 & 0.40 & 0.53 \\
\hline M2 & 0.39 & 0.53 \\
\hline M3 & 0.40 & 0.53 \\
\hline M4 & 0.36 & 0.53 \\
\hline M5 & 0.36 & 0.53 \\
\hline M6 & 0.36 & 0.53 \\
\hline M7 & 0.35 & 0.53 \\
\hline M8 & 0.34 & 0.53 \\
\hline M9 & 0.34 & 0.53 \\
\hline M10 & 0.48 & 0.53 \\
\hline M11 & 0.48 & 0.53 \\
\hline M12 & 0.47 & 0.53 \\
\hline M13 & 0.44 & 0.53 \\
\hline M14 & 0.45 & 0.53 \\
\hline M15 & 0.44 & 0.53 \\
\hline M16 & 0.42 & 0.53 \\
\hline M17 & 0.42 & 0.53 \\
\hline M18 & 0.42 & 0.53 \\
\hline M19 & 0.67 & 0.53 \\
\hline M20 & 0.65 & 0.53 \\
\hline M21 & 0.66 & 0.53 \\
\hline M22 & 0.60 & 0.53 \\
\hline M23 & 0.60 & 0.53 \\
\hline M24 & 0.60 & 0.53 \\
\hline M25 & 0.57 & 0.53 \\
\hline M26 & 0.56 & 0.53 \\
\hline M27 & 0.56 & 0.53 \\
\hline M28 & 0.84 & 0.53 \\
\hline M29 & 0.84 & 0.53 \\
\hline M30 & 0.84 & 0.53 \\
\hline M31 & 0.77 & 0.53 \\
\hline M32 & 0.76 & 0.53 \\
\hline M33 & 0.76 & 0.53 \\
\hline M34 & 0.73 & 0.53 \\
\hline M35 & 0.73 & 0.53 \\
\hline M36 & 0.72 & 0.53 \\
\hline
\end{tabular}

where $v(\mathrm{~m} / \mathrm{s})$ is the velocity at cross-section, $k$ is the velocity coefficient, $h(\mathrm{kPa})$ is pressure difference of inlet and outlet, and $x$ is flow stance index.

Regression analyses were conducted for the 36 simulation results according to (3) and the regression coefficients are presented in Table 3.

As shown in Table 3, for different combinations of structural parameters, Venturi tube flow index, $x$, was about 0.53 and fairly constant. This is consistent with the criteria of flow discrimination pattern in microirrigation emitter suggesting that the flow is turbulent flow. In addition, the structural parameters had little effect on flow stance index $x$ while they had greater effect on velocity coefficient $k$.

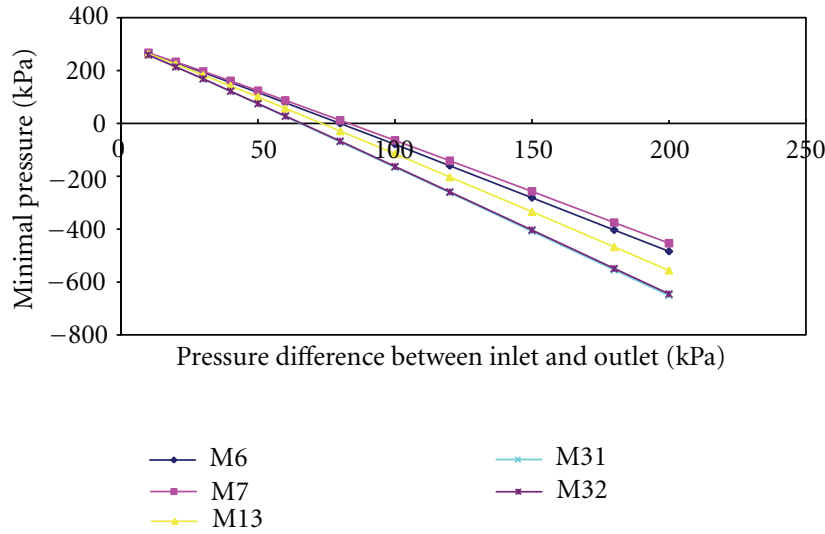

Figure 3: Lines of pressure differences and minimum pressure of Venturi injector.

3.2. Pressure Difference and the Minimal In-Tube Pressure. The simulations showed that the minimal in-tube pressure always occurred at the junction of contraction section and the throat of Venturi injector (Figure 2).

At a given inlet pressure, the minimal in-tube pressure would decrease with the increase of pressure difference between the inlet and outlet. For instance, when the inlet pressure was $100 \mathrm{kPa}$ and pressure difference between the inlet and outlet was increased from 10 to $60 \mathrm{kPa}$, the minimal intube pressure of treatment M1 would decrease from 62 to $-146 \mathrm{kPa}$. When the pressure difference between the inlet and outlet was determined, the minimal in-tube pressure would increase with the increase of the inlet pressure, and the quantitative relationship was presented as follows:

$$
H_{1}-H_{2}=h_{1}-h_{2} \text {, }
$$

where $H_{1}, H_{2}(\mathrm{kPa})$ are different inlet pressures, $h_{1}, h_{2}$ are the minimal in-tube pressures corresponding to $H_{1}$ and $\mathrm{H}_{2}$, respectively. Taking the treatment $\mathrm{M} 1$ as an example, when the pressure difference is $60 \mathrm{kPa}$, and the inlet pressure increases in sequence from $100 \mathrm{kPa}, 150 \mathrm{kPa}, 200 \mathrm{kPa}$ to $300 \mathrm{kPa}$, the minimal in-tube pressure would be $-146 \mathrm{kPa}$, $-96 \mathrm{kPa},-46 \mathrm{kPa}$, and $54 \mathrm{kPa}$ in sequence, with the same increase amplitude as inlet pressure.

Through a conversion of minimal in-tube pressure according to (4), the minimal in-tube pressures at different pressure differences with an inlet pressure of $300 \mathrm{kPa}$ were obtained (Figure 3), and regression analysis was conducted according to the following equation (5). The regression coefficients are showed in Table 4

$$
h_{\min }=m \cdot h+h^{\prime},
$$

where $h_{\min }(\mathrm{kPa})$ is the minimal in-tube pressure, $m$ is the coefficient of pressure difference, $h^{\prime}(\mathrm{kPa})$ is the ideal pressure, and $h(\mathrm{kPa})$ is the pressure difference between inlet and outlet.

The correlation lines of all pressure differences and the minimal pressures intersected at one point (Figure 3). When the inlet pressure was $300 \mathrm{kPa}$ and the pressure difference 
TABLE 4: Regression coefficient of minimum pressure and pressure differences of Venturi injector.

\begin{tabular}{|c|c|c|}
\hline Simulation & $m$ & $h_{\min }$ \\
\hline M1 & -4.33 & 311 \\
\hline M2 & -4.30 & 313 \\
\hline M3 & -4.31 & 311 \\
\hline M4 & -3.97 & 312 \\
\hline M5 & -3.95 & 312 \\
\hline M6 & -3.96 & 312 \\
\hline M7 & -3.80 & 312 \\
\hline M8 & -3.74 & 311 \\
\hline M9 & -3.78 & 312 \\
\hline M10 & -4.38 & 312 \\
\hline M11 & -4.47 & 312 \\
\hline M12 & -4.40 & 312 \\
\hline M13 & -4.32 & 313 \\
\hline M14 & -4.31 & 313 \\
\hline M15 & -4.32 & 315 \\
\hline M16 & -3.98 & 312 \\
\hline M17 & -3.98 & 313 \\
\hline M18 & -3.99 & 313 \\
\hline M19 & -4.99 & 312 \\
\hline M20 & -4.94 & 313 \\
\hline M21 & -4.88 & 312 \\
\hline M22 & -4.75 & 314 \\
\hline M23 & -4.79 & 315 \\
\hline M24 & -4.76 & 315 \\
\hline M25 & -4.33 & 313 \\
\hline M26 & -4.35 & 314 \\
\hline M27 & -4.35 & 314 \\
\hline M28 & -5.06 & 309 \\
\hline M29 & -5.12 & 310 \\
\hline M30 & -5.08 & 310 \\
\hline M31 & -4.80 & 312 \\
\hline M32 & -4.77 & 312 \\
\hline M33 & -4.81 & 313 \\
\hline M34 & -4.44 & 312 \\
\hline M35 & -4.45 & 312 \\
\hline M36 & -4.44 & 312 \\
\hline
\end{tabular}

between inlet and outlet was 0 , the minimum in-tube pressure is $312.6 \mathrm{kPa}$. When the liquid in the tube was the ideal liquid (the ideal liquid has neither the wall friction, nor the viscous force), and the pressure difference between the inlet and outlet was 0 , the fluid maintained a uniform linear motion, movement only occurred with the conversion of kinetic energy and potential energy, meanwhile there was no energy exchange with the environment. In this ideal state, the maximal pressure within the tube would be the $312.6 \mathrm{kPa}$. According to (4) and (5), the following expression can be obtained:

$$
h_{1}^{\prime}-h_{2}^{\prime}=H_{1}-H_{2},
$$

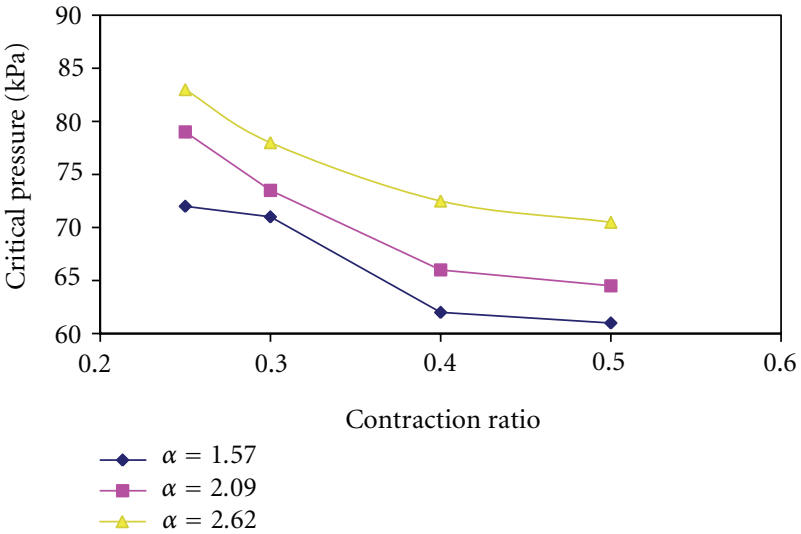

FIGURE 4: Effects of throat contraction ratio on critical pressure of Venturi injector.

where $h_{1}^{\prime}, h_{2}^{\prime}(\mathrm{kPa})$ are the ideal pressures corresponding to the inlet pressure of $\mathrm{H}_{1}, \mathrm{H}_{2}$, respectively.

Therefore, the minimum in-tube pressure could be calculated with the following expression:

$$
h_{\min }=m \cdot h+h_{\min }^{\prime}+H,
$$

where $h_{\min }^{\prime}(\mathrm{kPa})$ is the ideal pressure under the inlet pressure of $0 \mathrm{kPa}$, and $H(\mathrm{kPa})$ is the inlet pressure.

3.3. The Effect of Structural Parameters on Critical Pressure Difference. Structural parameters have great effects on minipressure and Venturi injector flow (average velocity at the cross-section of the outlet). Through statistical analysis, the main structural parameters influencing the flow mainly include the throat contraction ratio, throat taper, throat diameter, contraction length, contraction ratio, the expansion part, and the throat length. The effects of the throat contraction ratio, throat taper, and throat diameter on the hydraulic performance were more significant.

When the inlet pressure was determinate and the minimum in-tube pressure was 0 , the pressure difference between inlet and outlet $h_{\mathrm{cr}}$ could be obtained according to (7). When the pressure difference was greater than $h_{\mathrm{cr}}$, the minimum in-tube pressure was negative; otherwise, the minimum intube pressure was positive. In this study, $h_{\mathrm{cr}}$ was defined as critical pressure difference between inlet and outlet and can be calculated as follows:

$$
h_{\mathrm{cr}}=-\frac{H+h_{\mathrm{min}}^{\prime}}{m},
$$

where $h_{\mathrm{cr}}(\mathrm{kPa})$ is critical pressure difference between the inlet and outlet.

When inlet pressure was $300 \mathrm{kPa}$, thus $h_{\mathrm{cr}}$ were calculated with (8). The effects of throat contraction ratio on $h_{\text {cr }}$ were analyzed, and the fitting curves are shown in Figure 4.

As shown in Figure 4, when the throat contraction ratio was determined, critical pressure would increase with the increase of contraction taper (not cleaner). So Venturi injector should be designed to obtain optimal negative pressure, when the throat contraction ratio is determinate; throat 


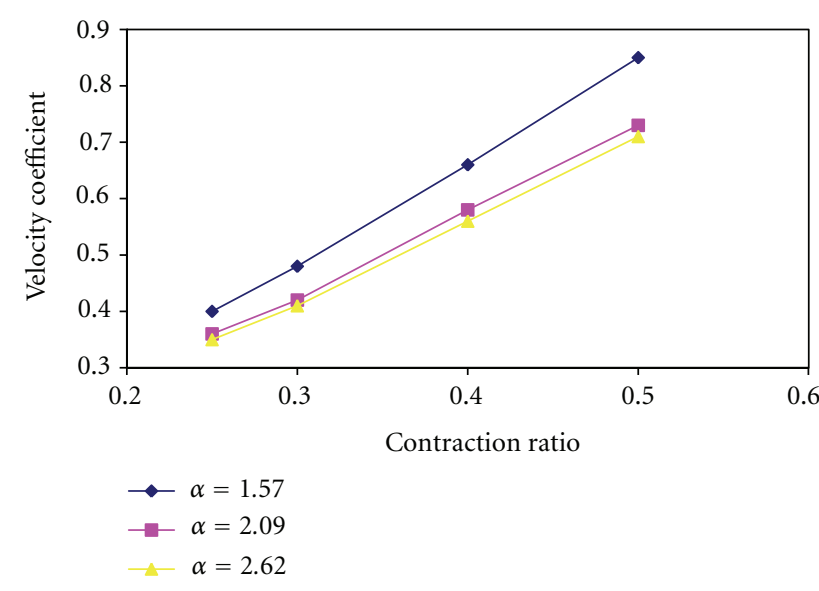

FIGURE 5: Effects of throat contraction ratio on velocity coefficient of Venturi injector.

taper should be appropriately shortened to get less head loss at optimal negative pressure and optimal fertilization effect. When contraction ratio was determinate, a negative correlation between $h_{\mathrm{cr}}$ and contraction ratio was demonstrated. That is to say, when the inlet pressure is given and other structural parameters remain constant, negative pressure is more easily to be obtained at the throat inlet. With the increase of throat contraction ratio, $h_{\mathrm{cr}}$ decrease would slow down. It is suggested that designing Venturi injector, contraction ratio would be reasonably selected, not to be too small.

3.4. Effect of Structural Parameters on the Outlet Velocity. When the inlet pressure was determined, the flow velocity was mainly determined by the throat contraction ratio and the contraction taper, but throat contraction ratio was more influential. As showed in Table 3, the regression value of the flow index at different treatments was constantly about 0.53. That is to say, the effect of structural parameters on the flow rate is its effect on the flow velocity coefficient $k$. The effects of throat contraction ratio and contraction taper on the flow velocity coefficient $k$ were comprehensively analyzed, and the correlation curve of flow velocity between the throat contraction ration and contraction taper were mapped (Figure 5).

The velocity coefficient $k$ tended to decline over the increase of throat taper, but the change would slow down gradually (Figure 5). The velocity coefficient $k$ showed a tendency to increase with the increase of throat contraction ratio, and the tendency would speed up gradually. Therefore, the local head loss of Venturi injector would increase with the increase of throat taper or throat contraction ratio, while the mean velocity at outlet cross-section would decrease. Based on regression analysis, the equation of velocity coefficient with the diameter in $50 \mathrm{~mm}$ was as follows:

$$
k=0.1131+1.6469 \lambda_{1}-0.0767 \alpha, \quad R^{2}=0.9944 .
$$

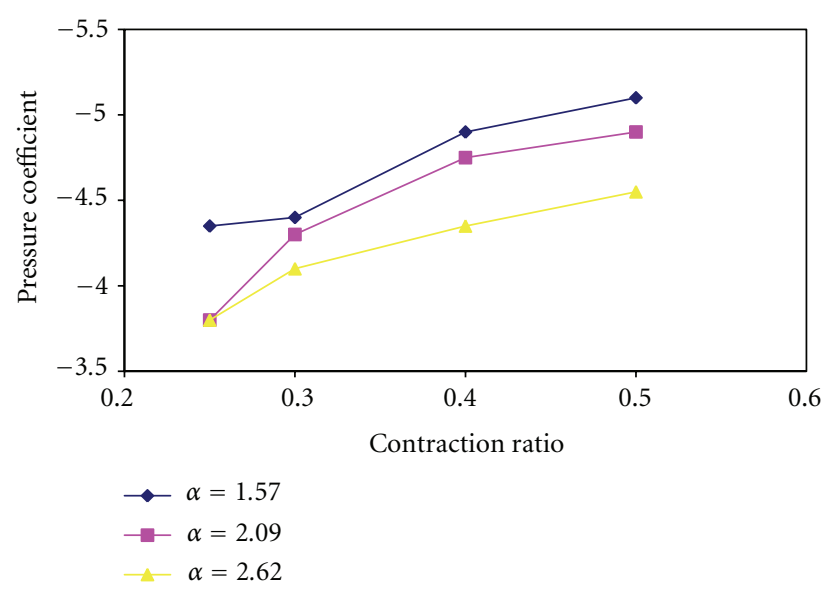

FIGURE 6: Effects of throat contraction ratio on pressure coefficient of Venturi injector.

3.5. Effects of Venturi Structural Parameters on the Minimum Pressure in the Tube. The effect of Venturi structural parameters on minimum pressure is the effect on the pressure difference coefficient $m$. Through statistical analysis, the effects of throat contraction ratio and contraction taper on minimum pressure were more significant than effects of other structural parameters. According to the results in Table 4 , the effects of throat contraction ratio $\alpha$ and contraction taper on the pressure difference coefficient $m$ were analyzed, and the correlation curve of $m$ with throat contraction ratio and contraction taper was established (Figure 6).

As shown in Figure 6, $m$ and its contraction taper showed a positive correlation, which indicated that contraction taper greatly affects the pressure distribution. In order to obtain optimal negative pressure, throat taper should be appropriately increased. Negative correlation demonstrated between $m$ and throat contraction ratio, $m$ decreased with the increase of throat contraction ratio, and the decrease would slow down. That is to say, when the inlet and outlet diameters remained unchanged, and other structural parameters are kept constant, the absolute minimum pressure would increase with the increase of tube diameter at throat. When the throat contraction ratio is $\leq 0.5$, if the throat diameter is too small, the flow velocity at the throat would be too large, and thus easily causes vaporization, which is not conducive to produce good negative pressure. Therefore, the throat diameter should be appropriately increased to produce effective intake negative pressure. $m$ could also be expressed in the following equation:

$$
m=-4.4030-3.1284 \lambda_{1}+0.5290 \alpha, \quad R^{2}=0.963 .
$$

3.6. Effects of Structural Parameters on Head Loss and Fertilizer Absorption Ratio. Due to the small length of venturi injector, the frictional head loss can be ignored in calculation, and the calculation formula of local head loss is as follows:

$$
h_{j}=\zeta \frac{v^{2}}{2 g},
$$


where $h_{j}(\mathrm{~m})$ is local head loss, which stands for the pressure difference between inlet and outlet in this study, $\zeta(\%)$ is the coefficient of local head loss, $v(\mathrm{~m} / \mathrm{s})$ is the average flow speed of outlet section, and $g\left(9.8 \mathrm{~m}^{2} / \mathrm{s}\right)$ is acceleration of gravity.

Local head loss $\zeta$ was calculated through (11). The results showed that the local head loss of Venturi injector was very great. The value of $\zeta$ tested here is between 2.25 and 13.27. When contraction ratio $\lambda_{1}$ is between 0.25 and 0.50 , the value of $\zeta$ would drop quickly with the increase of $\lambda_{1}$, while other structure parameters had little influence on $\zeta$, so it can be expressed approximately like that $\zeta=0.5 \lambda_{1}^{-2.16}$. In addition, it is also found that coefficient of local head loss $(\zeta)$ fell with the increase of the pressure difference, which may be caused by the change of flow pattern. Using Reynolds number to analyze the flow pattern in tube through the following formula:

$$
R_{e}=\frac{v d}{v}
$$

where $R_{e}(\%)$ is Reynolds number, $v$ stands for kinematic viscosity coefficient of water $\left(\mathrm{m}^{2} / \mathrm{s}\right)$, when the temperature is $20^{\circ} \mathrm{C}, v=1.01 \times 10^{-6} \mathrm{~m}^{2} / \mathrm{s}$.

The calculation results of (12) show the Reynolds number is between $14356 \sim 335643$, so it is turbulence due to the criterion of hydraulics. Besides, the Reynolds number, the mutual movement inside water flow, the energy conversion caused by mutual movement increase with the pressure difference, while the proportion of energy conversion caused by function between fluid and structure would decrease, which well-explained why the local head loss would decrease with the increase of pressure difference.

It is generally agreed that effective Venturi injector should have small coefficient of local head loss but greater fertilizer absorption ratio $(\eta)$. The driving flow rate and the minimum pressure in tube of main tube were established in this study. Therefore, the amount of fertilizer absorption can be predicted in accordance with the tube hydraulics. Suppose there was a standard atmospheric pressure on liquid fertilizer surface, and the distance under the Venturi tube was $0.5 \mathrm{~m}$, the diameter of fertilizer absorption tube was $8 \mathrm{~mm}$, without considering local head loss, the amount of fertilizer absorption can be predicted according to the following equation:

$$
q=A \sqrt{2 g h_{0}}
$$

where $q\left(\mathrm{~m}^{3} / \mathrm{s}\right)$ is the amount of fertilizer absorption, $h_{0}$ is the head difference of fertilizer absorption tube between outlet and inlet, which means distance difference between liquid fertilizer surface with Venturi tube.

The results showed that fertilizer could be stably absorbed when the contraction ratio $\lambda_{1}$ was bigger than $(0.4$ or 0.5$)$, the pressure difference between outlet and inlet was $80 \mathrm{kpa}$, and $\eta$ was 0.5 . However, when the contraction ratio $\lambda_{1}$ was less than 0.3 , it may absorb fertilizer stably only when the pressure difference between outlet and inlet is $100 \mathrm{kpa}$. And when the pressure difference between outlet and inlet remained constant, $\eta$ showed a tendency to decrease with the increase of contraction ratio $\lambda_{1}$.

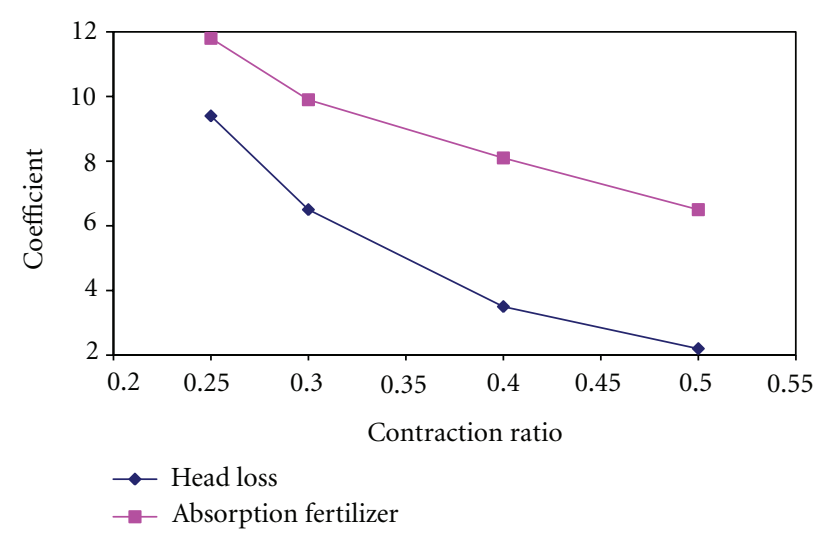

FIGURE 7: Effects of contraction ratio on head loss and absorption fertilizer of Venturi injector.

Figure 7 shows the correlation among the contraction ratio, local head loss, and fertilizer absorption ratio, when the pressure difference between outlet and inlet is $150 \mathrm{kPa}$, the pressure of inlet is $300 \mathrm{kPa}$. It can be found that the coefficient of local head loss and $\eta$ would decline with increase of contraction ratio. Therefore, the throat diameter cannot be too big or too small when designing the Venturi injector; and it should be chosen in accordance with coefficient of local head loss and the diameter of throat part. The throat length has little influence on the critical pressure, the minimum pressure in tube, and the flow speed, which is in consistence with the findings in the literature.

\section{Conclusions}

(1) It is demonstrated that a strong relationship between the mean velocity at outlet section and the pressure difference, and the flow stance index was approximately 0.53 ; velocity coefficient was mostly influenced by throat taper and throat contraction ratio.

(2) The minimum pressure occurred in the throat inlet wall, and the location of minimum pressure was rarely influenced by the opening position and pore size of Venturi injector. There existed perfect linear relation between the minimum pressure and the pressure difference between at inlet and outlet. When the inlet pressure is determined, the curves of the pressure difference and the minimum pressure would come cross a fixed point. The coordinates of the point were not influenced by the pressure difference at the inlet and outlet.

(3) The structural parameters which influence the hydraulic performances of Venturi injector include throat taper, throat contraction ratio, throat length, and expansion section taper. More significant influence of throat contraction ratio was found among parameters affected by hydraulic performances. The results showed a positive correlation between the throat contraction ratio and the mean velocity at outlet section, and a negative correlation between throat contraction ratio and minimum pressure in tube. 
(4) The results showed a negative relationship between coefficient of local head loss, absorption fertilizer ratio, and throat contraction ratio. So it is strongly recommended that when designing Venturi injector, contraction ratio should be reasonably selected according to the coefficient of local head loss and absorption fertilizer ratio.

\section{Acknowledgments}

This work is jointly supported by China 863 Plan (2011AA100507).

\section{References}

[1] S. Z. Kang, X. T. Hu, H. J. Cai, and S. Y. Feng, "New ideas and development tendency of theory for water saving in modern agriculture and ecology," Journal of Hydraulic Engineering, vol. 35, no. 12, pp. 1-7, 2004.

[2] W. Q. Niu, P. T.Wu, and X. K. Fan, "Low-pressure drip irrigation system," Water Saving Irrigation, vol. 2, pp. 29-30, 2005.

[3] W. Niu, P. Wu, and X. Fan, "Method for calculating integrated flux deviation rate of micro-irrigation system," Nongye Gongcheng Xuebao/Transactions of the Chinese Society of Agricultural Engineering, vol. 20, no. 6, pp. 85-88, 2004.

[4] F. S. Li and S. N. Lu, "Study on the fertigation and it s application," Plant Nutrition and Fertilizer Science, vol. 6, no. 2, pp. 233-240, 2000.

[5] S. J. Hou, "Design on two par s pattern venturi tube," Drainage and Irrigation Machinery, vol. 13, no. 4, pp. 44-46, 1995.

[6] Y. Sha and S. J. Hou, "Experimental research on applying fertilizer apparat us of parallel Venturi tubes," Drainage and Irrigation Machinery, vol. 13, no. 2, pp. 37-39, 1995.

[7] X. M. Sheng, "Introduction of 100Ps-1 Venturi fertilizer applicator," Water Saving Irrigation, vol. 11, pp. 14-15, 2000.

[8] X. Y. Sun and S. Y. Wu, "Introduction of fertilizer applicator by pressure difference," Water Saving Irrigation, vol. 5, pp. 36-37, 2003.

[9] B. J. Li, H. P. Mao, and K. Li, "A study on the parallel connection Venturi tube and its parameter selection," Drainage and Irrigation Machinery, vol. 19, no. 1, pp. 42-45, 2001.

[10] Y. K. Jin, C. H. Xia, and B. L. Fang, "Research and development of Venturi fertilizer applicator series," China Rural Water and Hydropower, vol. 5, pp. 14-16, 2006.

[11] Z. B. Chen, H. J. Dou, S. W. Chen et al., "Numeral research on flow field of Venturi tube," China Building Material Equipment, vol. 4, pp. 61-63, 2005.

[12] M. Wang, X. Huang, and G. Li, "Numerical simulation of characteristics of Venturi Injector," Transactions of the Chinese Society of Agricultural Engineering, vol. 22, no. 7, pp. 27-31, 2006. 

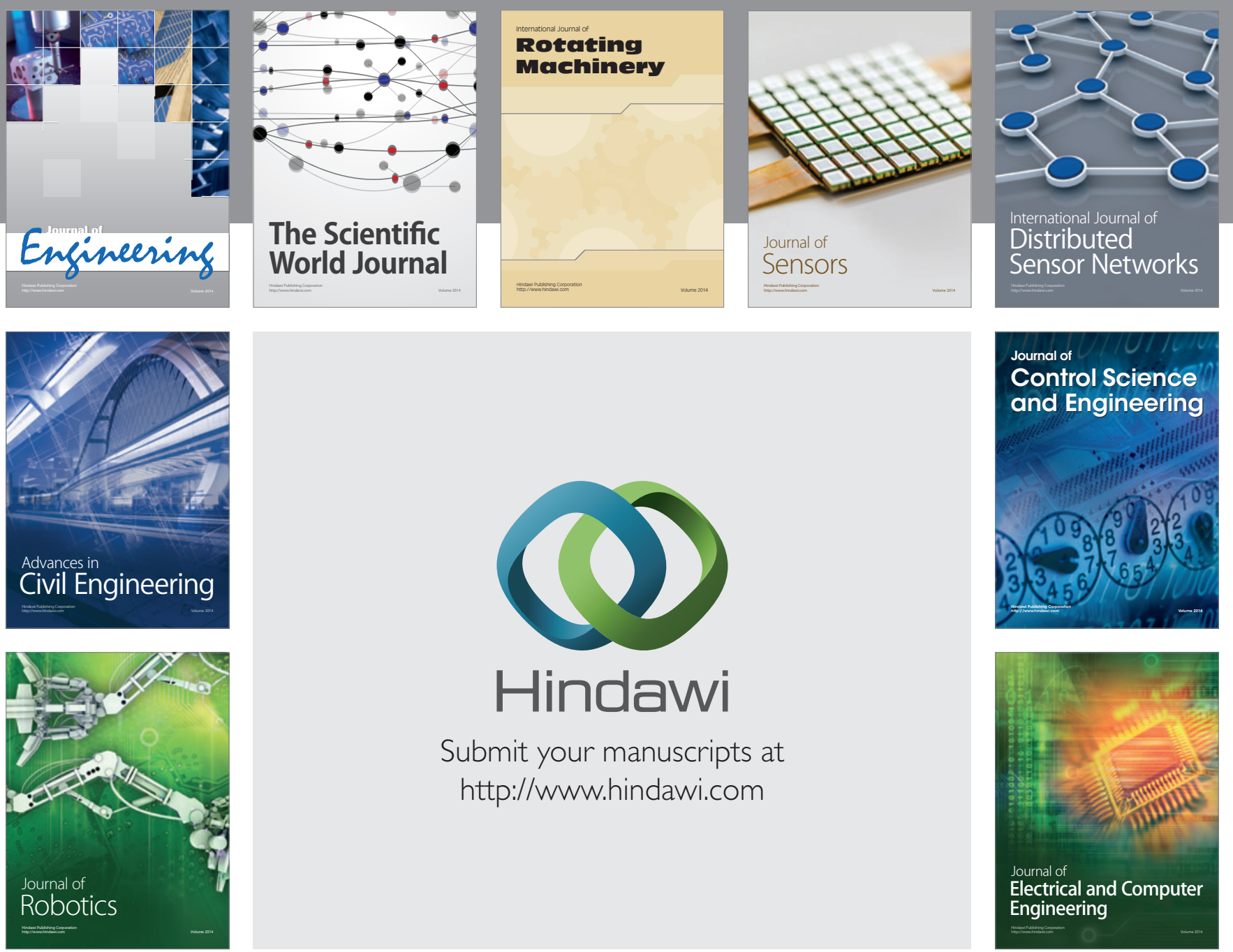

Submit your manuscripts at

http://www.hindawi.com
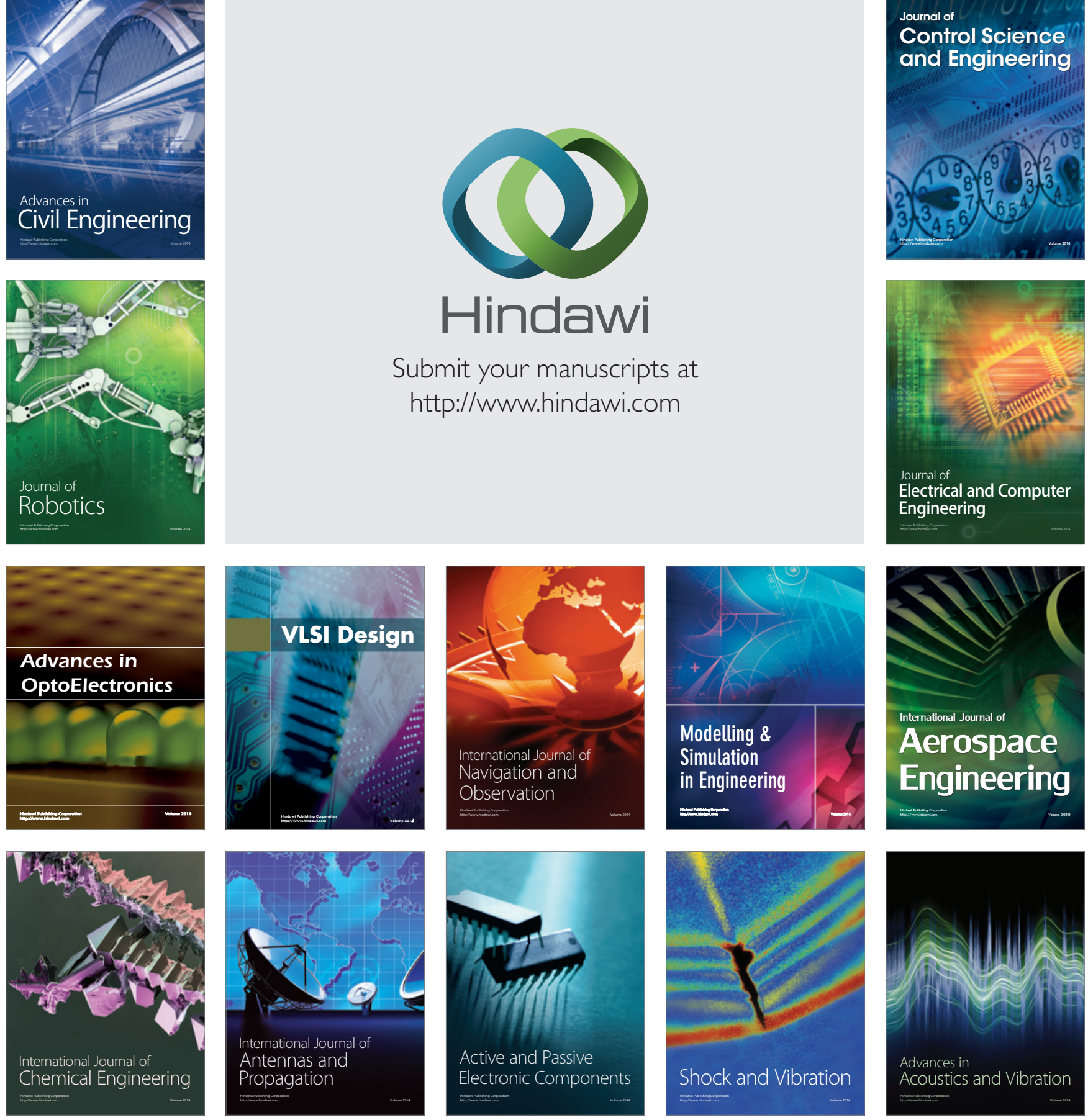